\begin{abstract}
Accelerator Division
Alternating Gradient Synchrotron Department

BROOKHAVEN NATIONAL LABORATORY

Upton, New York 11973
\end{abstract}

Accelerator Division

Technical Note

AGS/AD/Tech. Note No. 388

\title{
MAGNETIC FIELD MEASUREMENTS OF THE SuperEBIS SUPERCONDUCTING MAGNET
}

\author{
A. Hershcovitch, A. Kponou, R. Clipperton, W. Hensel, F. Usack
}

January 24, 1994

SuperEBIS was designed to have a solenoidal magnetic field of a 5 Tesla strength with a $120 \mathrm{~cm}$ long bore. The field was specified to be straight within 1 part in 10000 within the bore, and uniform to within 1 part in 1000 within the central $90 \mathrm{~cm}$. This was for an operating mode in which the end coils are used to flatten the axial profile.

Figure 1 shows the magnet structure. The superconducting magnet consists of nine coils, five of which form the main solenoid with four compensation coils. Two pairs of two coils each are independent bucking coils. In the main solenoid, the main coil section (\#1 in Figure 1) has 36,085 turns, on top of which at both ends there are end compensation coils (\#2 and \#3 in Figure 1) consisting of 1,498 turns each. Located $30 \mathrm{~cm}$ from the center at either side there are two additional compensation windings (\#4 and \#5 in Figure 1) of 46 turns each. All these coils are powered by a single supply.

Each pair of bucking coils can be energized independently. Each bucking coil consists of two coil sections. In each, one coil (\#6 or \#7 in Figure 1) consisting of about 2,420 turns, is located at the end of the main solenoid, while the second coil (\#8 or \#9 in Figure 1), consisting of 476 turns, is wound on top of the main solenoid. The coils are connected in series, such that the current 
circulates in the opposite direction in the coil that is wound on top of the solenoid (\#8 or \#9) to cancel the effect of the outer coil (\#6 or \#7) on the central field region.

Magnetic field measurements were performed with a computerized magnetic field measuring setup [1] that was borrowed from W. Sampson's group. The results are displayed in Figures 2-11. In some of these figures, MC, UC, and LC designate main coil, upper coil, and lower coil, respectively.

A comparison between Figures 2 and 3 indicates that at the fields of interest to us, magnetization (trapped) field effects are unimportant.

In Figure 5, two sets of data are displayed. The reason for the"scale up" to $40 \mathrm{~A}$ is an accidental loss of the $40 \mathrm{~A}$ data that occurred while the $36.5 \mathrm{~A}$ data was loaded into the computer. Figures 6 and 7, as well as Figures 8 and 9 show that (the compensation effects) of the compensating coils do indeed work well. We had a pleasant surprise in our ability to operate the bucking coils in the bucking mode since previous attempts to do so failed. The failures were attributed to fabrication errors.[2]

A preliminary test was made of a scheme to determine if the magnetic and mechanical axes of the solenoid coincided, and, if not, by how much. This is described in more detail in the Appendix.

We would like to thank Bill Sampson, Arup Ghosh, and Ken Robins for lending and helping us with their magnetic measurement setup.

\section{$\underline{\text { References }}$}

[1] A.K. Ghosh, K.E. Robins, and W.B. Sampson, Supercollider 4, 755, Edited by J. Nontes, Plenum Press, 1992.

[2]. R. Schmieder, et al., Rev. Sci. Instrum. 61, 259 (1990). 
$\measuredangle Z \underset{\text { Former }}{\text { Aluminum }}$

Bucking

Coils(6-9) $\square$ Main Solenoid (1 - 5)

Winding Cheeks
Tufnol/GRP

$7^{6}{ }^{8}+1$

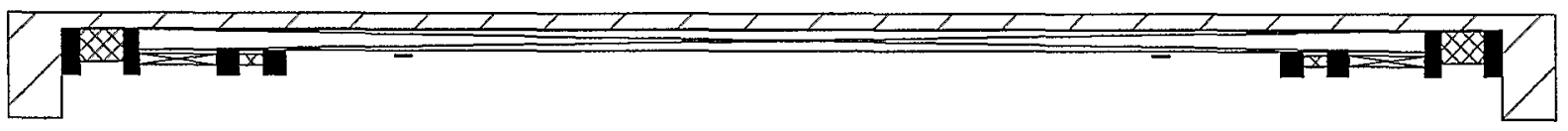

Figure 1. The Superconducting Solenoid of SuperEBIS. 


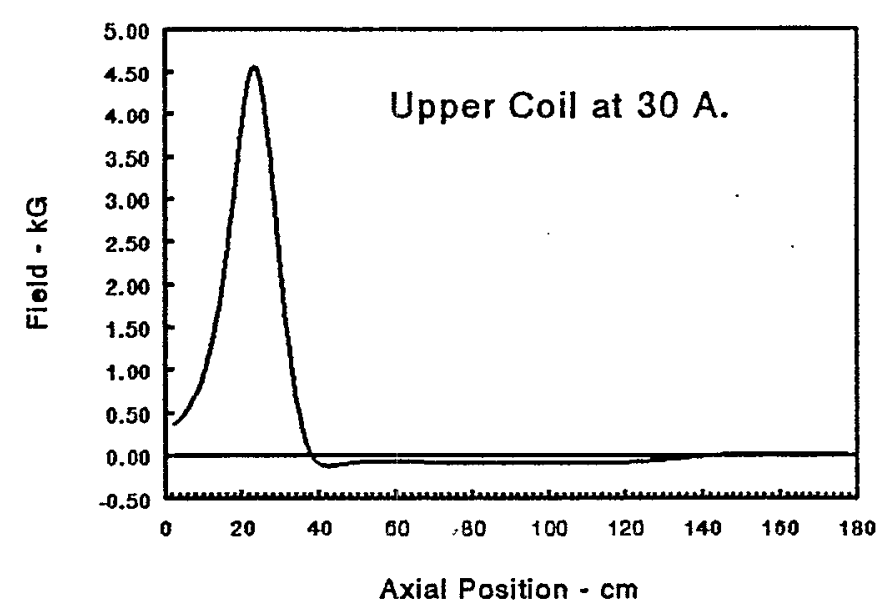

Figure 2. Field profile of upper

bucking coil energized to $30 \mathrm{~A}$.

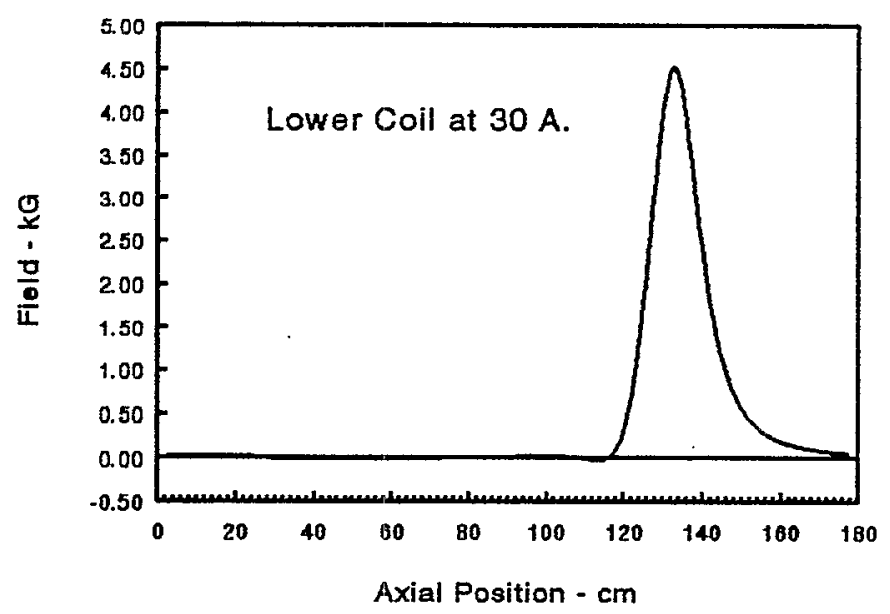

Figure 4. Profile of lower bucking coil energized to $30 \mathrm{~A}$.

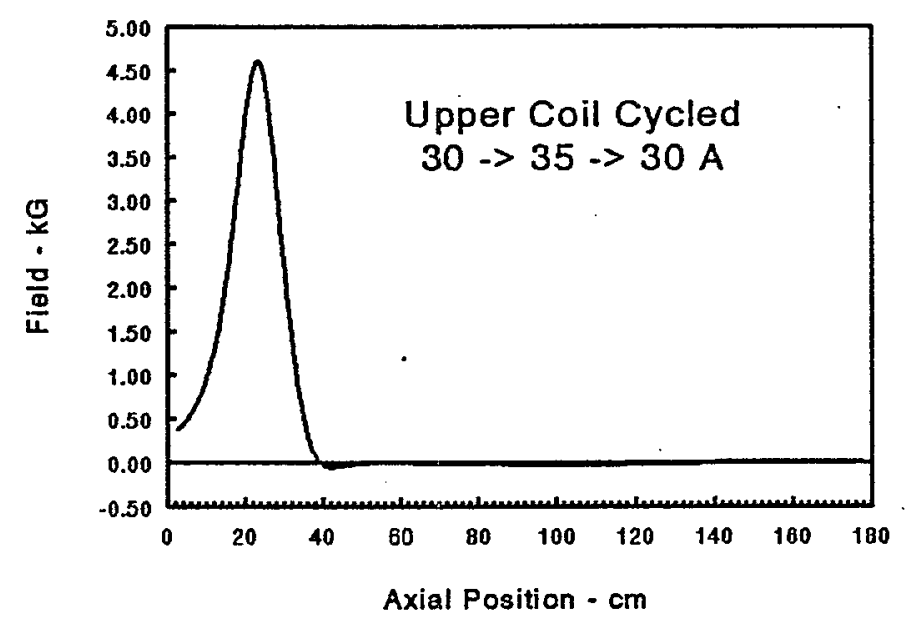

Figure 3. Profile after cycling upper coil to $35 \mathrm{~A}$.

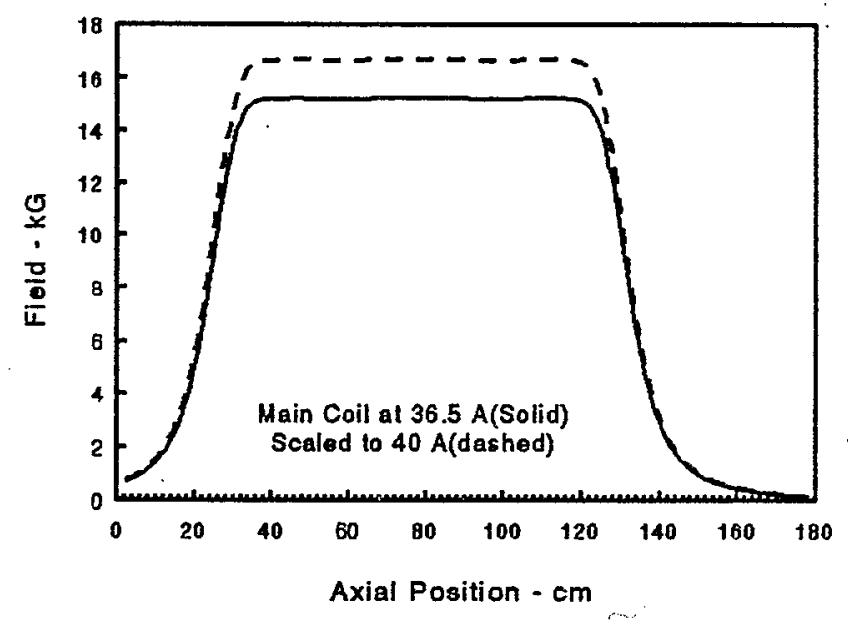

Figure 5. Field profile of main coil energized to $36.5 \mathrm{~A}$ (solid line) and scaled to $40 \mathrm{~A}$ (dashed line). 


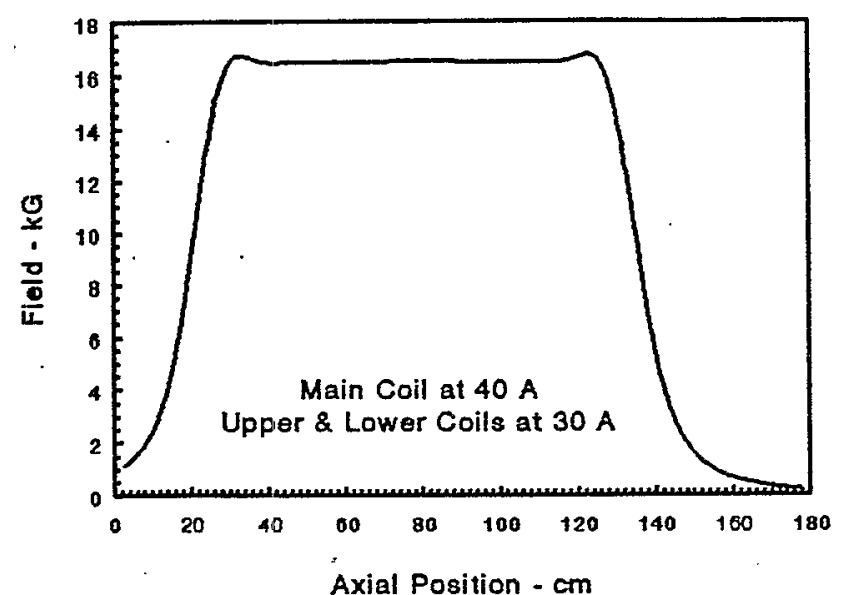

Figure 6. Main coil at $40 \mathrm{~A}$ and bucking coils at $30 \mathrm{~A}$.

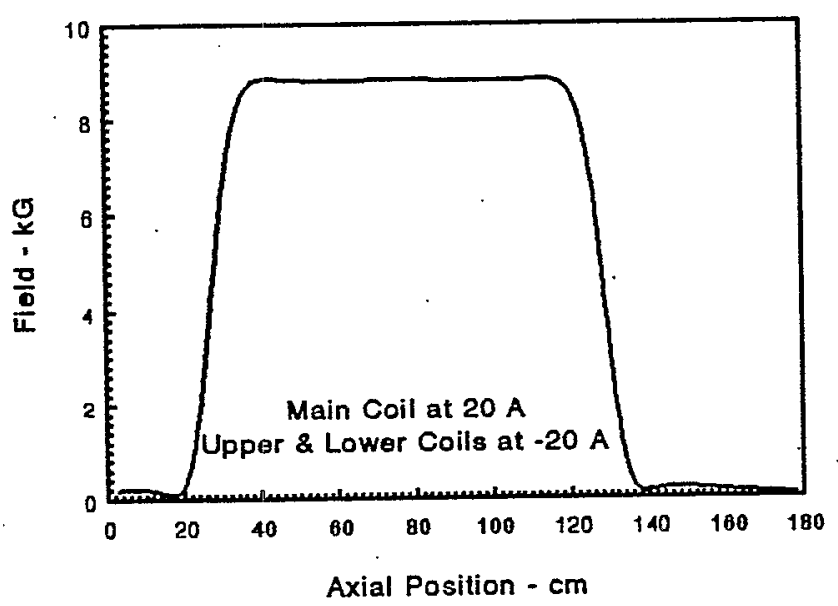

Figure 8. Main coil at $20 \mathrm{~A}$, and bucking coils at $-20 \mathrm{~A}$.

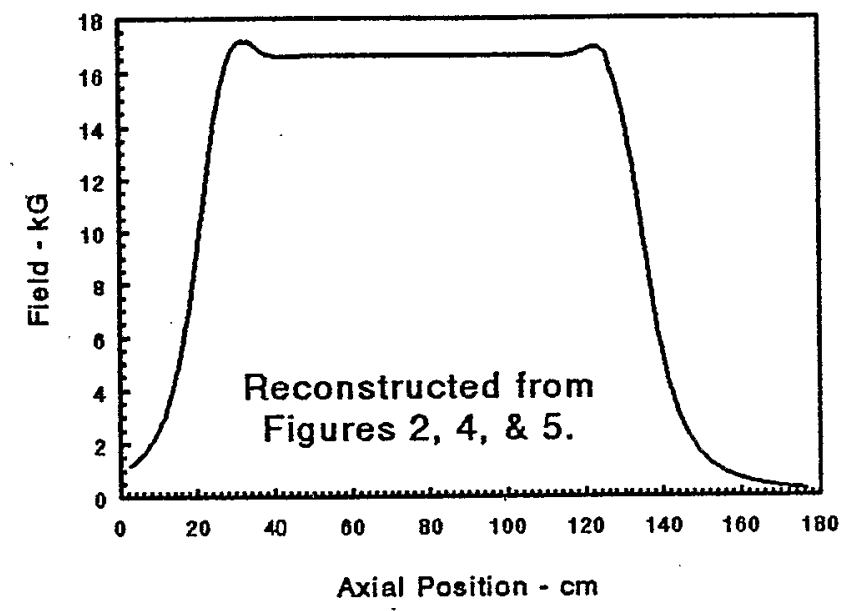

Figure 7. Reconstructed result in Figure 6 from data used in Figures 2, 4, and 5 (with some scaling).

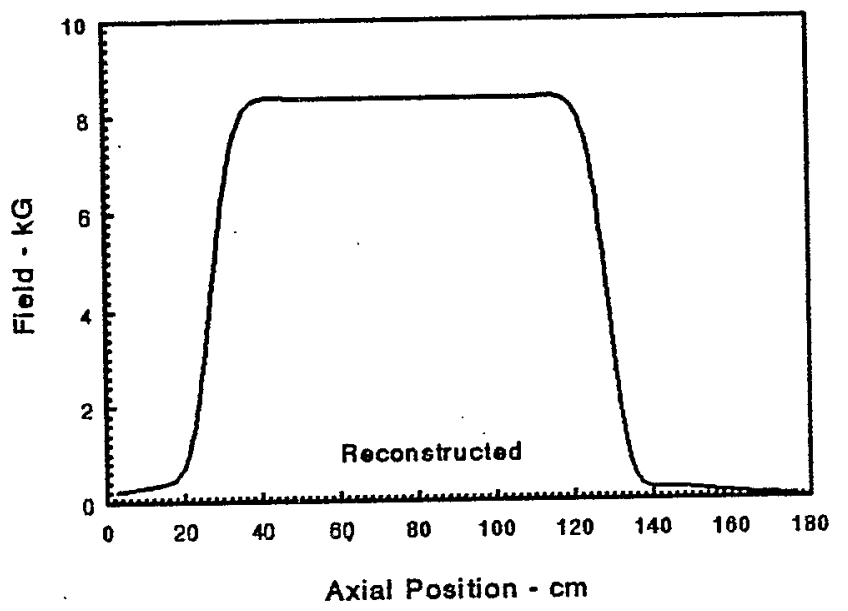

Figure 9. Reconstructed profile in Figure 8 from data used in Figures 2, 4, and 5 (with scaling). 


\section{A P P E N D I X}

Referring to Figure A.1, the axes are perpendicular, or very nearly so, to the plane of the figure. (The Hall probe is assumed to rotate about the mechanical axis, and it can also be moved along the axis.) When the probe is rotated as shown in the fringe fields where the field has a radial component, the field measured is given by:

$$
B(\theta)=B_{r} \cdot \cos (\alpha(\theta)) \cdot\left|\frac{\frac{d}{d \theta} \alpha(\theta)}{\frac{d}{d \theta} \alpha(\theta}\right|
$$

(Remove one of the absolute value signs in A.1 if $\mathrm{dR}>\mathrm{RP}$.)

$$
\begin{gathered}
B_{r}=k \cdot R(\theta) \\
R(\theta)=\sqrt{R P^{2}+d R^{2}-2 \cdot d R \cdot \cos (\pi-\theta)} \\
\alpha(\theta)=\sin ^{-1}\left[\left(\frac{d R}{R(\theta)}\right) \cdot \sin (\pi-\theta)\right]
\end{gathered}
$$

The $\cos (\alpha(\theta))$ term in A.1 is present because the probe is not always perpendicular to $B_{r}$. The linear relationship in $A .2$ was verified up to $R \approx 3.5$ $\mathrm{cm}$ by plotting the results of a computer calculation for different distances from the midplane.

The main fitting parameter for A.1 to the data is dR. But we also varied $\mathrm{k}$, assuming we had not correctly estimated the distance from the midplane and RP. The data and best visual fit are shown in Figure A.2.

The values of the fitting parameters obtained were: $\mathrm{dR}=1.2 \mathrm{~mm}, \mathrm{k}=$ $277 \mathrm{G} / \mathrm{cm}$, and $\mathrm{RP}=9.5 \mathrm{~mm}$. From the magnet calculation, this value of $\mathrm{k}$ is obtained approximately $3 \mathrm{~cm}$ closer to the midplane.

If we note that the extrema in $\mathrm{B}_{\mathrm{r}}$ occur when the probe is collinear with the axes, then, by determining the origin of the rotation and repeating the measurement at other axial positions of the probe, we can construct a 3-D picture of the misalignment. A combination of circumstances made it impossible to repeat the measurements at other axial positions. 
In the analysis, we have neglected the fact that the plane of rotation of the probe may not be perpendicular to the magnetic axis. This introduces a $\cos (\phi)$ type correction, to $\mathrm{B}_{\mathrm{r}}$ where $\phi$ will usually be a small angle.

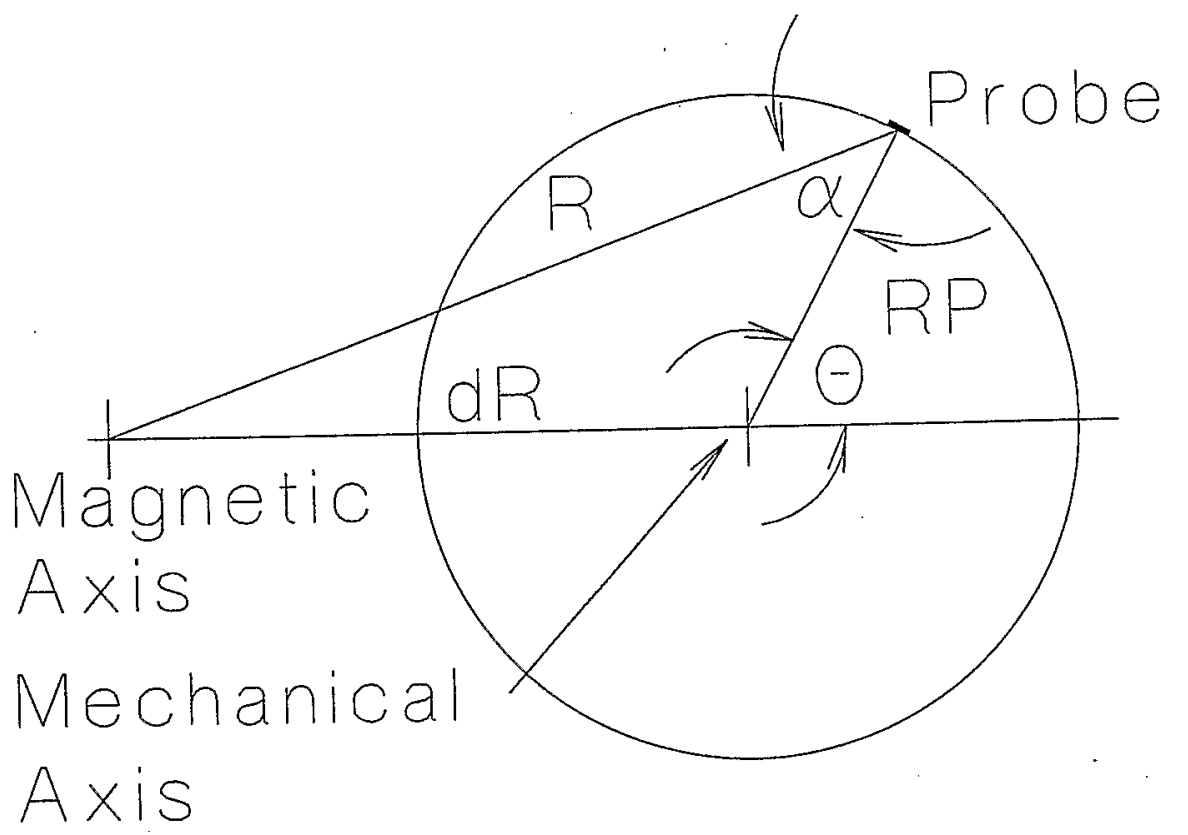

Figure A.1 - Scheme to determine $d R$ by measuring $B_{r}$ vs $\Theta$.

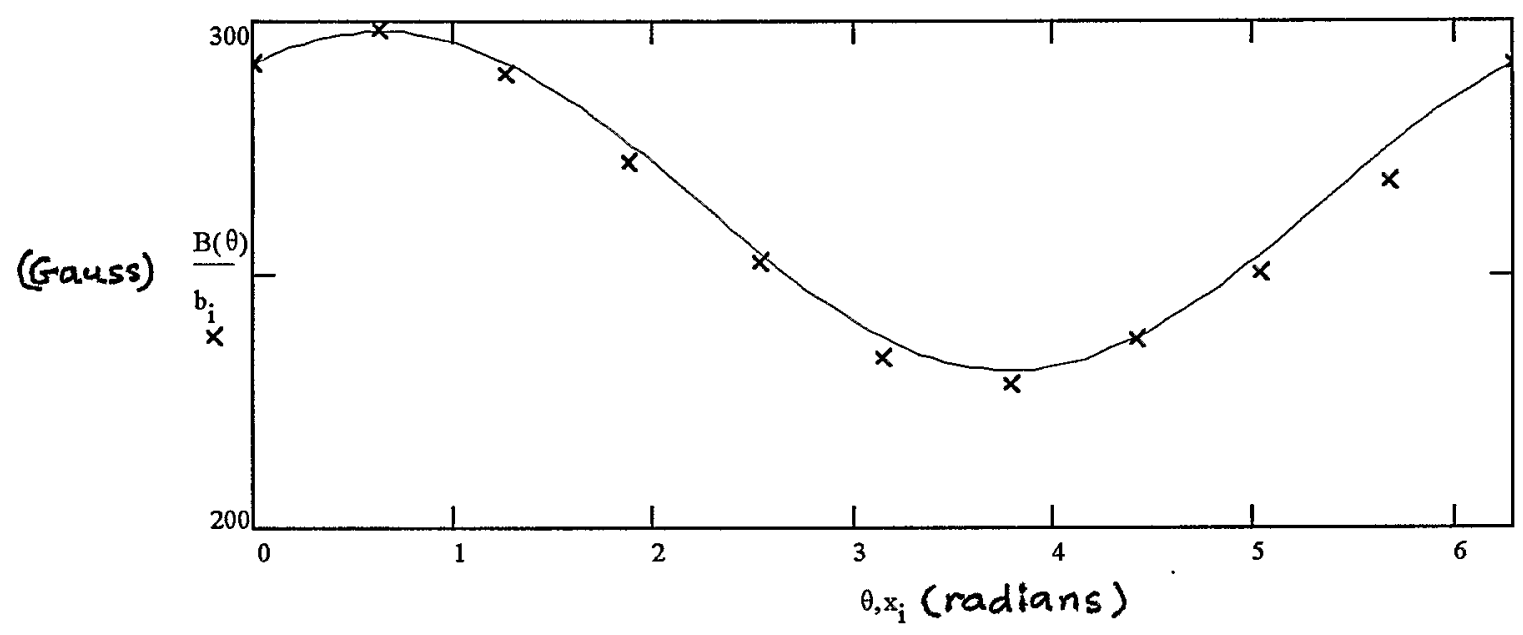

Figure A.2 - Magnetic field (in Gauss) vs angular position ( $\Theta$ ) of the Hall probe in Figure A.1. Points are the measured data, solid line is the fit of Equation A.1. 